they affect hairdressers, who use them repeatedly and often, rather than their clients, whose exposure by comparison is brief and occasional.

A dramatic and distressing result of shampooing with anionic detergents is for the hair to become matted into a bird's nest that no ingenuity can disentangle, for the hairs have become welded together. ${ }^{3}$ The only solution is to cut off the tangle, after which the hair regrows normally. The extreme rarity of this happening compared with the commonplace use of this type of shampoo, makes it difficult to offer any credible explanation, particularly since the same detergent has been used again later with impunity. Hairs can become felted by the physical entanglement of the tile-like scales with which they are covered, as occurs in wigs made of human hair that has been mounted without paying attention to which end of the hair is which. Friction facilitates such felting ${ }^{4}$ and is believed to be the cause of the bird's nests seen in patients who fiddle with and rub their hair obsessively (plica neurotica), but rubbing has not been a particularly prominent feature in the histories of the shampoo cases. Other mechanisms suggested have been electrostatic attraction and viscous fluid weldingthe welding effect is apparent under the scanning electron microscope-but there is no real explanation of the precise circumstances concerned. Perhaps the biggest clue is that the central area of the scalp is worst affected and that peripheral parts may be normal. It is tempting to speculate that conditions are favourable when an undiluted solution of anionic detergent is brought into contact with hair that is either dry or scarcely wet. This is no more than conjecture, though it may be significant that all the patients seem to have been doing their own shampooing.

1 Savill, A, and Warren, C, The Hair and Scalp, 5th edn. London, Arnold, 1962.

${ }^{2}$ Fisher, A A, Contact Dermatitis, 2nd edn. Philadelphia, Lea and Febiger, 1973.

${ }^{3}$ Dawber, R P R, and Calnan, C D, Clinical and Experimental Dermatology, 1976, 1, 155.

4 Bogaty, H, and Dunlap, F E, Archives of Dermatology, 1970, 101, 348.

\section{Mental health reforms}

The Mental Health Act 1959 was in all probability the most important instrument of English legislation yet devised in its effects on the mentally disordered. Yet there were imperfections in its conception-imperfections which have become increasingly apparent in the last 17 years. No matter what, it is likely that the Act would have had to be revised. Nevertheless, an element of urgency was introduced by the tragic failures in the existing procedures in the cases of two men who committed murders of a particularly spectacular and gruesome kind while on conditional discharge from Broadmoor special hospital.

Last month the DHSS published a consultative document, ${ }^{1}$ the work of a committee made up of various government departments whose task it was to consider what amendments should be made to the Act. The committee had been given the benefit of suggestions from professional bodies and individuals: a review submitted by the Royal College of Psychiatrists ${ }^{2}$; the results of the lengthy deliberations of a specially appointed working party; the report ${ }^{3}$ of the Butler Committee (which was concerned with all legislation appertaining to the mentally abnormal offenders including part $\mathrm{V}$ of the Act); and the findings of a one-man inquiry by an American lawyer published under the aegis of MIND. ${ }^{4}$

The term "mental disorder" was introduced in the 1959 Act to cover all forms of mental illness or disability of mind. Of the four statutory sub-categories, the one that has come in for major criticism is "psychopathic disorder." The Butler Committee admitted in its report that to recommend the deletion of the term was outside its remit, but it gave cogent reasons why this should be done, of which by far the weightiest was the continuing uncertainty whether the condition is treatable in a medical sense. Practising psychiatrists would in the main agree; and very few would weep if, despite the legal difficulties, behaviour disorders in general were to be no longer a primary medical responsibility. In this context, the Butler Committee put forward proposals for the training and treatment of dangerous antisocial psychopaths on a voluntary basis in special units, but within the penal system. The Royal College in turn suggested a new definition and classification of "mental disorder," but omitted any reference to psychopathy. It pointed out, however, that if necessary such individuals requiring to be detained and treated under civil orders could be dealt with under "any other disorder or disability of mind," an integral part of the suggested definition. This would have particular relevance when, or (perhaps more pertinently) if, the new regional secure units come into being.

One of the underlying principles on which the 1959 Act was based was that as much treatment as possible, both inpatient and outpatient, should be on an informal (voluntary) basis. Indeed, this policy has been successful : about $90 \%$ of all admissions to hospital and virtually all outpatients are on an informal basis. But there remain, and will always remain, that minority for whom compulsion is necessary. The Royal College is satisfied with the present provisions of part IV of the 1959 Act. MIND, however, would narrow the criteria for compulsory admission to relate more closely to dangerousness to self or others or to grave disablement. The committee maintains, very sensibly, that criteria of this sort would be disadvantageous to those persons suffering from dementia-for example, who are too confused to be able to state or realise their needs. On the other hand, it thought that MIND's narrower criteria might be applied when the time came for the renewal of a compulsory order.

Some sharp criticism of the shorter compulsory orders (sections 25, 29, and 136) was made by MIND; but this view was not shared by either the Royal College or the committee, which has opted for their retention. It must be emphasised that just because these short orders-and in particular section 29 (admission for observation in emergency) and in the Metropolitan area section 136 (place of safety) - are frequently used it does not necessarily mean that they are being abused. The possible alternative to these emergency measures is a 24-hour crisis-intervention service, but the committee points to the inescapable fact that neither the skilled manpower nor the resources are available.

The second part of the consultative document considers the protection of the patient, the staff, and the public. An innovation in the 1959 Act, and perhaps its most important protection against the abuse of compulsory powers, were the mental health review tribunals (MHRTs). In practice, the present powers of MHRTs are "all or nothing," which may explain how conditionally discharged patients succeeded in committing serious offences. To lessen this danger, the committee acknowledges the need for the powers of the MHRT to be extended so as to allow discharges to be delayed until suitable after-care arrangements are made-in effect the opinion held by the 
Royal College and the Butler Committee. The committee also suggest that tribunals should have the right to recommend transfer, trial leave, and conditional discharges and that such recommendations would be expected to carry considerable weight. MIND, on the other hand, suggested that tribunals should be given a wide range of statutory powers. This, the committee considers, would be for the most part impracticable and probably counterproductive because of the woeful lack of aftercare facilities in the community.

It would be as well to emphasise the continuing decline in the number of applications for MHRTs. Of those detained under sections 26 and 60 , there has been a steady drop from 732 in 1970 to 500 in 1974, whereas references to tribunals remained fairly constant at about 370 a year. One good reason for the decline in applications is that to abscond from a local (conventional) mental hospital is considered to be almost a right-and a far more expeditious and far less troublesome way of leaving hospital.

On the vexed topic of the consent to treatment the arguments advanced vary widely. There is most merit in the Butler formula that "treatment (other than nursing care) shall not be imposed on any patient without his consent if he is able to appreciate what is involved"; and the committee suggests that only treatment intended to prevent violence, save life, or prevent deterioration should be carried out without consent and that a second (medical) opinion should be sought when the treatment proposed is irreversible or hazardous.

The committee also considered the power of the courts to remand a mentally disordered person charged with a criminal offence to hospital before deciding his ultimate disposal. While to remand such a person to prison may be at least unhelpful and at worst inhumane, all alternative suggestions must surely acknowledge the fact (which the committee seems to ignore) that there is virtually no security in local mental hospitals. It would be totally unacceptable if in these circumstances the defendant could abscond at will; and the same objection could be raised to the suggested "interim hospital order." Again the answer lies in the proposed regional security units, which alone could carry out such a holding operation. But there is no tangible evidence that these vital units will materialise in the foreseeable future. Without them not only will so many of the suggested amendments to the 1959 Act be impossible to carry out but the credibility of the invaluable Act could itself be thrown into jeopardy. There can be no better illustration of the reality of this threat than is seen in the recent increase in the instances in which frustrated judges have had to award inappropriate prison sentences, sometimes life sentences, to men because there are no beds available in the special hospitals, and because local hospitals, quite rightly, decline to accept them.

${ }^{1}$ DHSS, A Review of the Mental Health Act, 1959. London, HMSO, 1976. 2 Review of the Mental Health Act, 1959: Report of the Working Party of the Public Policy Committee. News and Notes Supplement to the British Fournal of Psychiatry, October and November 1974 (vol 125). Report of the Committee on Mentally Abnormal Offenders, Cmnd 6244. London, HMSO, 1975.

4 Gostin, L O, A Human Condition: The Mental Health Act from 1959 to 1975. Observations, Analysis and Proposals for Reform. MIND (National Association for Mental Health), 1975.

\section{Antibiotics for respiratory illness?}

The proper use of antibiotics in common respiratory tract infections is still a matter of controversy. On the one hand, there is long habit, pressure from patients, their families, and the pharmaceutical industry, and the doctor's fear that he may leave untreated an illness which might worsen and endanger the patient. Against all that has to be set the paucity of evidence that such respiratory illnesses are benefited, the unwanted effects of drug treatment on the individual patient, and the remorseless march of antibiotic drug resistance in the community. Just as antibiotic resistance in bowel organisms has an importance far wider than the treatment of gut infection, so drug resistance in organisms of the respiratory tract affects not only our options in treating respiratory infection but also other and often more dangerous diseases-witness the recent emergence of ampicillin resistance in Haemophilus influenzae and its implications for the treatment of childhood meningitis. ${ }^{1}$

The diagnosis of the cause of any respiratory tract infection is usually impossible on clinical evidence, and we are often uncertain whether such infections are viral, bacterial, or both. If we had more precise and more rapid diagnostic methods they would certainly help to define and refine the use of antibiotics. Methods such as transtracheal aspiration and lung puncture are applicable only for selected seriously ill patients in hospital, ${ }^{2}$ and others such as the use of counter-current immunoelectrophoresis $^{3}$ may yet find a place in diagnosis in the community. But at present the laboratory has little to offer the general practitioner treating respiratory tract infections in patients well enough to stay at home. Here the most fruitful progress is by way of controlled trials in carefully defined groups of patients with respiratory tract illnesses.

For the ordinary run of upper respiratory tract illnesses antibiotics neither shorten the course of the illness nor prevent bacterial complications ${ }^{4}{ }^{5}$ and it seems probable that their widespread use does not, contrary to popular belief, lessen the number of return consultations in general practice. ${ }^{6}$ In this issue (p 556) Stott and West describe a study of patients seen in general practice with cough and purulent sputum but no abnormal signs in the chest (a group especially hard to assign to known pathogens). They found that minocycline gave no advantage over placebo in speed of recovery, though the patients given antibiotics had fewer episodes of upper respiratory infection in the ensuing six months. Their findings are especially interesting since purulent sputum is usually taken as a positive indication for antibiotic administration. The curve showing their patient's rate of improvement is both a useful piece of natural history and a refutation of the notion, widespread though implicit in much antibiotic prescribing, that reduction in their use will at once be followed by a spate of illnesses of the type seen in the preantibiotic era. These patients did not in fact develop pneumonia, empyema, lung abscess, or septicaemia: they simply got better and went back to work-just as quickly in those given placebo as in those given antibiotics.

1 Smith, A L, New England fournal of Medicine, 1976, 294, 1329.

2 Davidson, M, Tempest, B, and Palmer, D L, fournal of the American Medical Association, 1976, 235, 158.

${ }^{3}$ Perlino, C A, and Shulman, J A, fournal of Laboratory and Clinical Medicine, 1976, 87, 496.

${ }^{4}$ Soyka, L F, et al, Pediatrics, 1975, 55, 552.

5 Gordon, M, Lovell, S, and Dugdale, A E, Medical fournal of Australia, 1974, 1, 304.

${ }^{6}$ Howie, J G R, et al, fournal of the Royal College of General Practitioners, $1971,21,657$. 